\title{
Otimização do consumo de aço de Sistemas Verticais de Vedação em Light Steel Framing para diferentes espaçamentos em Protótipo de Habitação De Interesse Social (HIS)
}

\section{Optimization of steel consumption of Light Steel Framing Vertical Fencing Systems for different spacings in Prototype of Housing of Social Interest (HSI)}

\author{
${ }^{1}$ Edgard Ribeiro Junior, ${ }^{2}$ Adnauer Tarquínio Daltro, ${ }^{3}$ Allyf Alves Kamakura \\ ${ }^{1}$ Mestrado em Engenharia de Edificações e Ambiental - Universidade Federal de Mato Grosso \\ (edgard@arqed.com.br) \\ ${ }^{2}$ Doutor em Ciências e Engenharia de Materiais - Universidade de São Paulo (adnauer@ufmt.br) \\ ${ }^{3}$ Engenheiro Civil - Universidade Federal de Mato Grosso (allyf.alves@gmail.com)
}

\begin{abstract}
RESUMO: O custo, velocidade de execução e a facilidade de produção em escala são características importantes a serem pensadas nas habitações de interesse social (HIS). Diante destas necessidades, o Light Steel Framing (LSF) é uma alternativa aos sistemas convencionais de concreto armado e alvenaria de vedação. $\mathrm{O}$ sistema LSF, classificado como construção à seco, possui os painéis estruturais como os elementos principais para dar forma e sustentação às edificações. Assim, vislumbrou-se a necessidade de se pensar em alternativas e projetos que minimizassem a taxa de utilização de aço nestas construções e, consequentemente, a obtenção de uma residência mais econômica. O presente trabalho procurou avaliar a taxa consumo de aço por metro quadrado a partir da variação dos espaçamentos dos montantes dos painéis estruturais LSF de uma habitação de interesse social. Foram elaborados três protótipos com os espaçamentos dos montantes distintos, sendo de $40 \mathrm{~cm}, 60 \mathrm{~cm}$ e $80 \mathrm{~cm}$. Os protótipos foram dimensionados de acordo com a NBR 14762:2010 fazendo uso do software Metálicas 3D. Os resultados obtidos dos protótipos do presente trabalho foram comparados entre si e entre o dimensionamento conduzido por Senra (2010) de um protótipo similar ao projetado. Os resultados verificados foram satisfatórios, no qual as taxas de consumo de aço dos três protótipos foram de $24,7 \mathrm{~kg} / \mathrm{m}^{2}, 23,2 \mathrm{~kg} / \mathrm{m}^{2} \mathrm{e}$ $21,9 \mathrm{~kg} / \mathrm{m}^{2}$, respectivamente, do menor para o maior espaçamento dos montantes. O protótipo, inicialmente dimensionado por Senra (2010), apresentou uma taxa de consumo de aço de $23,8 \mathrm{~kg} / \mathrm{m}^{2}$, sendo que, após a otimização conduzida neste trabalho, a taxa se reduziu para $21,9 \mathrm{~kg} / \mathrm{m}^{2}(7,98 \%)$. Conclui-se que ao aumentar o espaçamento entre os montantes é possível proporcionar uma redução satisfatória do consumo de aço e, consequentemente, redução custo das obras das HIS em LSF.
\end{abstract}

Palavras Chave: Metálica 3d. Painéis Estruturais. Habitação de Interesse Social.

\begin{abstract}
The cost, speed of execution and the facility of production in scale are important characteristics to be thought for Housing of Social Interest (HSI). Faced with these needs, Light Steel Framing (LSF) is an alternative to conventional reinforced concrete and masonry systems. These LSF system, classified as dry construction, has the structural panels as the main elements to give shape and support to the buildings. Faced with this question, it is possible to think about alternatives and projects that would minimize the rate of steel use in these constructions and, consequently, obtain a more economic buildings. The present work sought to evaluate the steel consumption rate per square meter from the variation of the studs of the LSF structural panels of a housing o social interest. Three prototypes were designed, with distinct studs spacings of $40 \mathrm{~cm}, 60 \mathrm{~cm}$ and 80 $\mathrm{cm}$. The prototypes were designed following the Brazilian NBR 14762: 2010 standard, by the use of Metálicas $3 \mathrm{D}$ software. The results obtained from the prototypes in the present work were compared among themselves and between those conducted by Senra (2010), which designed a prototype similar to the one utilized in this work. The results were satisfactory, in which the steel consumption rates of the three prototypes were $24.7 \mathrm{~kg} / \mathrm{m}^{2}$, $23.2 \mathrm{~kg} / \mathrm{m}^{2}$ and $21.9 \mathrm{~kg} / \mathrm{m}^{2}$, respectively, from the lowest to the largest spacing between the studs. The prototype, initially designed by Senra (2010), presented a steel consumption rate of $23.8 \mathrm{~kg} / \mathrm{m}^{2}$, and after the optimization conducted in this work, the rate was reduced to $21.9 \mathrm{~kg} / \mathrm{m}^{2}(7.98 \%)$. We conclude that, by increasing the spacing between the studs, it is possible to provide a satisfactory reduction of the steel consumption and, consequently, to provide a reduction in the cost of the HSI works in LSF.
\end{abstract}

Keywords: Metallic 3d. Structural Panels. Housing of Social Interest. 
Ribeiro Junior, Edgard; et al; Otimização dos sistemas verticais de vedação em light steel framing para um protótipo de habitação de interesse social. E\&S - Engineering and Science, 2019, 8:2.

\section{INTRODUÇÃO}

A adoção do Light Steel Frame (LSF) na construção de habitações de interesse social (HIS) tem grande potencial de inovação, visto que este sistema construtivo proporciona a redução do prazo executivo, pois diversas etapas são executadas nas fábricas, reduzindo a geração de resíduos em comparação ao sistema convencional em concreto armado e alvenaria.

$\mathrm{O}$ presente trabalho vem de encontro com esta demanda, a partir do desenvolvimento de um protótipo para habitação de interesse social (HIS) em LSF. Este projeto teve início com o trabalho de graduação de Abrão (2008). Desde então vem sendo desenvolvidas melhorias e adaptações no projeto original, como ocorreu com o trabalho de graduação de Senra (2010) que realizou o aperfeiçoamento e o dimensionamento estrutural do protótipo desenvolvido por Abrão (2008). Nesta etapa, o projeto teve outras contribuições na parte de materiais de revestimento e isolamento térmicos. A última grande contribuição no projeto arquitetônico do protótipo foi elaborada por Duarte (2017), que propôs mudanças no projeto arquitetônico que incorporou os requerimentos do Programa Minha Casa Minha Vida, sob os quesitos de sustentabilidade do Selo Casa Azul da Caixa Econômica Federal.

Com a adequação do projeto aos programas sociais do governo, tornou-se necessário o redimensionamento da estrutura para se adequar a nova realidade. Por meio de uma revisão de literatura sobre o tema, observou-se que a avaliação das taxas de consumo de aço para projeto HIS ainda são tratados de forma escassa. Portanto, este trabalho tem o objetivo de dimensionar e otimizar os painéis estruturais do projeto em light steel framing destinadas a habitações de interesse social (HIS). Usualmente, as normas técnicas americanas, manuais brasileiros e trabalhos encontrados na literatura sobre o tema indicam a adoção de espaçamento para os montantes a distância ideal de $60 \mathrm{~cm}$ visando estruturar adequadamente os painéis LSF. No entanto, com vista a adequar os painéis a realidade brasileira e aos projetos de HIS desenvolvidos no pais, buscou-se investigar se outros espaçamentos para os montantes (entre 40 a $80 \mathrm{~cm}$ ), poderiam fornecer taxas de consumo de aço por metro quadrado adequadas, visando não só reduzir o consumo mas também proporcionar maior flexibilidade aos projetos em LSF.

\section{REVISÃO BIBLIOGRÁFICA}

De acordo com Rodrigues e Caldas (2016) existem dois conceitos básicos relativos ao Sistema Light Steel Framing (LSF): Frame é o esqueleto estrutural projetado para dar forma e suportar a edificação, sendo constituído por componentes leves que são os perfis formados a frio (PFF) e Framing é o processo pelo qual se unem e vinculam esses elementos.

Santiago, Freitas e Crasto (2012) definem o sistema LSF como sendo um processo pelo qual compõe-se um esqueleto estrutural em aço formado por diversos elementos individuais ligados entre si, passando a dar forma à edificação e a resistir às cargas que a solicitam.

Por se tratar de um sistema destinado à construção de edificações, o sistema LSF não se resume apenas à sua estrutura. Ele é composto por vários componentes e subsistemas que, além do estrutural, existem o de fundação, isolamento termoacústico, de fechamento interno e externo, e instalações elétricas e hidráulicas como se observa na Figura 1 (SANTIAGO; FREITAS; CRASTO, 2012). 
Ribeiro Junior, Edgard; et al; Otimização dos sistemas verticais de vedação em light steel framing para um protótipo de habitação de interesse social. E\&S - Engineering and Science, 2019, 8:2.

Figura 1 - Desenho esquemático de uma residência em LSF

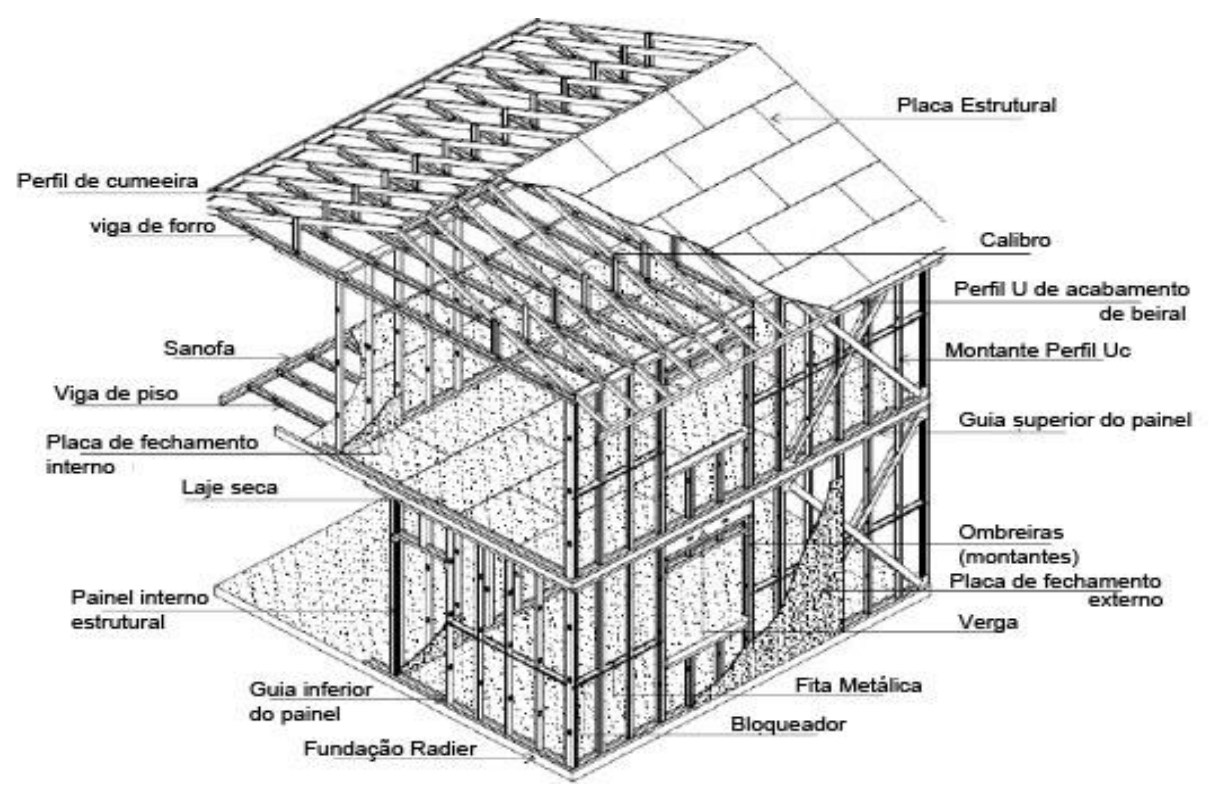

Fonte: Santiago, Freitas e Crasto (2012).

A adoção do LSF para construção de HIS tem grande potencial de inovação, visto que se trata de um sistema altamente industrializado, o que assegura um bom controle de qualidade dos materiais. Além disso, o LSF garante redução do prazo de execução, pois diversas etapas são executadas nas fábricas, imprimindo um maior ritmo à execução da obra, reduzindo a geração de resíduos e aprimorando o controle sobre a produção.

Estas características são ideais para a construção de HIS, pois assegura a produção de grande número de habitações, no menor prazo possível, com qualidade, rapidez, economia, redução de desperdícios às obras, proporcionando baixos custos e desempenho adequados as atuais necessidades do país.

Do ponto de vista do comportamento estrutural, os elementos estruturais possuem algumas diferenças em relação às demais estruturas como o aço laminado, soldado ou estruturas de concreto. Logo, para realizar o dimensionamento adequado deve-se entender estas particularidades. De acordo com Silva, Pierin e Silva (2014), estes elementos por serem constituído de perfis com seções abertas e de pequena espessura, podem ter problemas de deformações excessivas, instabilidade ou atingir os limites de resistência do aço devido a esforços de torção por conta da sua baixa rigidez à torção.

Com isso, o adequado dimensionamento das estruturas de seção aberta e chapas finas devem considerar não só esforços internos como os momentos fletores em torno dos eixos x e $\mathrm{y}$ e as forças cortantes na direção de $\mathrm{x}$ e $\mathrm{y}$, mas também o entendimento do fenômeno do empenamento e da distorção da seção transversal (SILVA, PIERIN E SILVA, 2014).

\section{MATERIAIS E MÉTODOS}

\subsection{Caracterização do objeto de pesquisa}

Utilizou-se como objeto de estudo o projeto arquitetônico indicado na Figura 2 e 3. Trata-se de unidade habitacional de interesse social (HIS) térrea, com uma área total construída de 59,24m², que contempla sete ambientes: dois quartos, sala, cozinha, banheiro, varanda e área de serviço.

Do ponto de vista estrutural, todas as paredes foram projetadas em LSF com exceção da parede que divide os quartos e da divisória existente entre a varanda e a área de serviço, nas quais se adotou o modelo drywall. $\mathrm{O}$ mesmo consiste em paredes não estruturais, com a 
Ribeiro Junior, Edgard; et al; Otimização dos sistemas verticais de vedação em light steel framing para um protótipo de habitação de interesse social. E\&S - Engineering and Science, 2019, 8:2.

função apenas de separação de ambientes. Elas possuem uma espessura menor do que os painéis estruturais, apresentando menor peso próprio que os painéis em LSF.

Além das cargas permanentes provenientes do sistema de vedação e da cobertura, considerou-se a instalação de duas caixas-d'água (500 litros), logo acima do banheiro. Desta forma, nestes locais se faz necessário projetar painéis mais resistentes. Nesse sentido, reduziuse nestes locais as distâncias entre montantes, de forma que se garantisse adequada distribuição dos esforços desde a cobertura até a fundação.

Figura 2 - Layout da alteração do protótipo
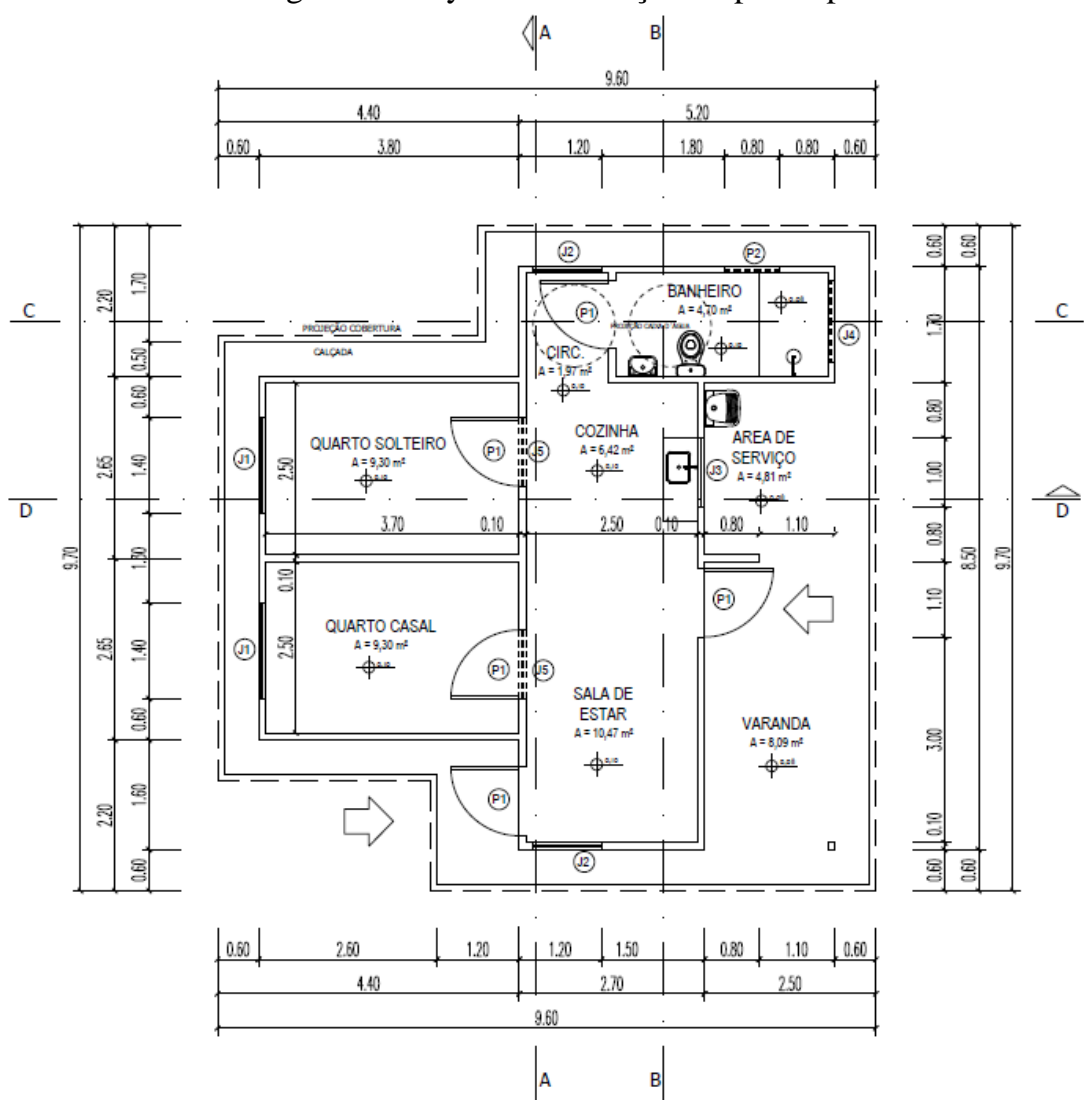

Cotas em metros

Fonte: Duarte, 2017.

Figura 3 - Fachadas do protótipo

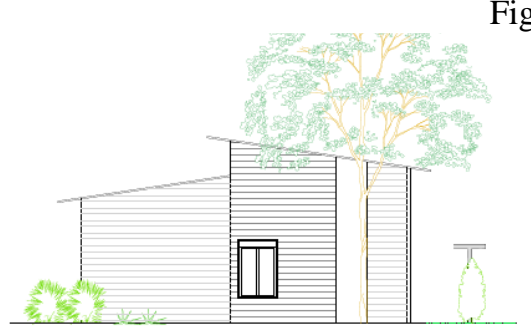

10 FACHADA FRONTAL

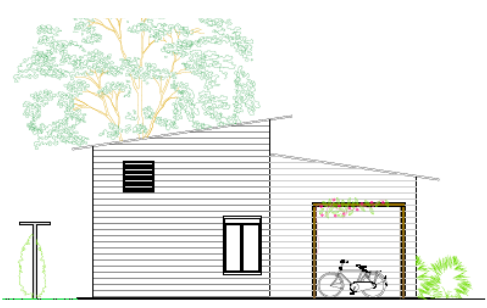

12 FACHADA POSTERIOR

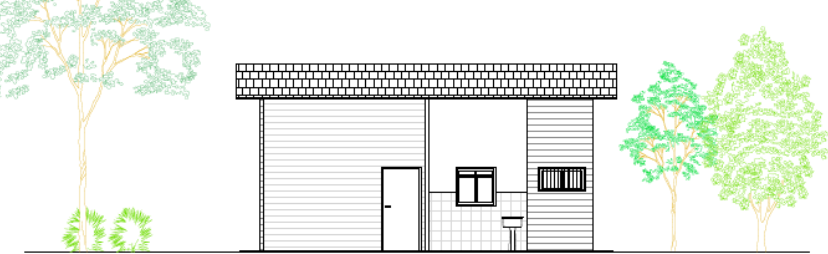

11 FACHADA LATERAL DIREITA

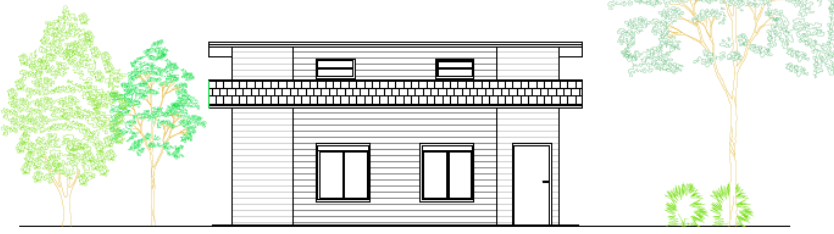

13 FACHADA LATERAL ESQUERDA

Fonte: Duarte, 2017. 
Ribeiro Junior, Edgard; et al; Otimização dos sistemas verticais de vedação em light steel framing para um protótipo de habitação de interesse social. E\&S - Engineering and Science, 2019, 8:2.

\subsection{Modelagem do sistema estrutural da edificação}

A partir do projeto padrão de habitação de interesse social, elaborou-se o sistema estrutural da edificação em Light Steel Frame, visando conduzir as analise e dimensionamento estrutural. O trabalho foca em análise comparativa em termos de consumo de aço por área construída entre os sistemas LSF com diferentes espaçamentos. Nesse sentido, foram realizados os cálculos de ações e esforços solicitantes para sistemas estruturais nos quais os montantes estavam espaçados de 40,60 e 80 centímetros conforme indicado da Figura 4 a 6. Para a analise estrutural e dimensionamento utilizou-se o programa Metálica 3D.

Figura 4 - Protótipo com montantes a cada $40 \mathrm{~cm}$

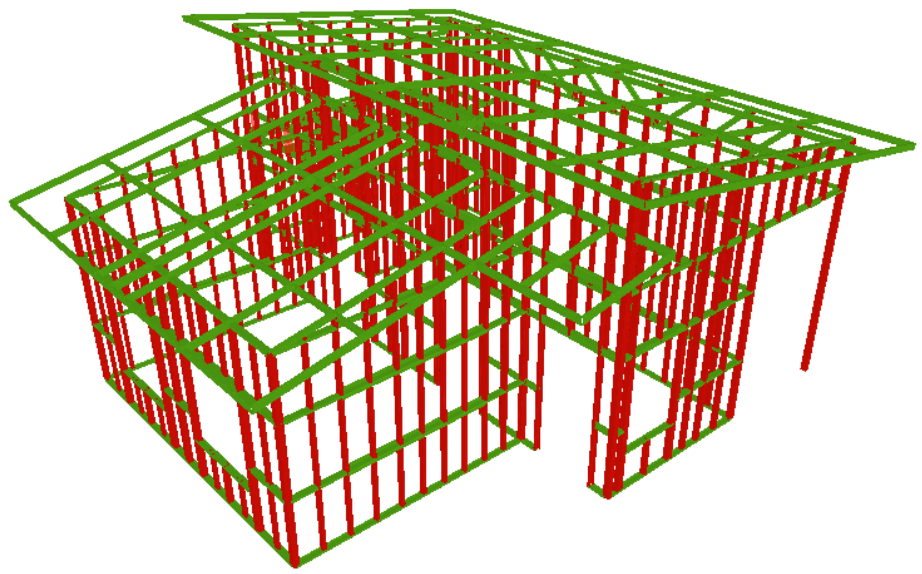

Figura 5 - Protótipo com montantes a cada $60 \mathrm{~cm}$

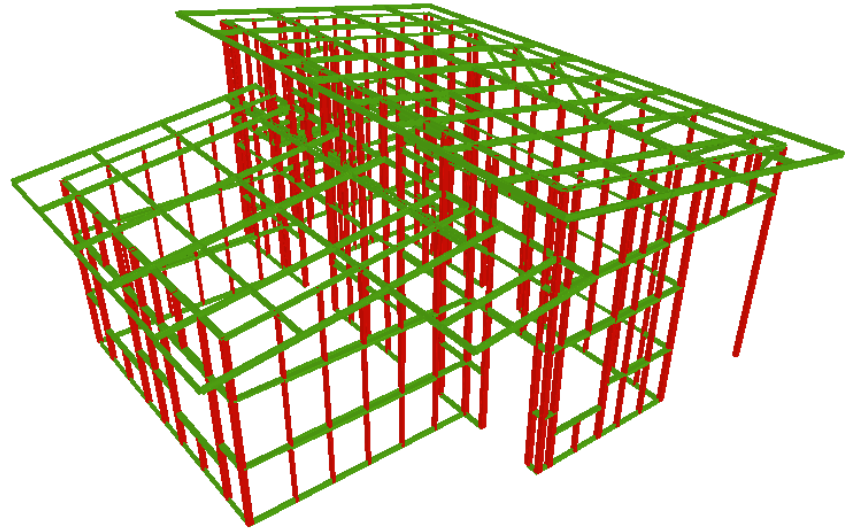

Figura 6 - Protótipo com montantes a cada $80 \mathrm{~cm}$

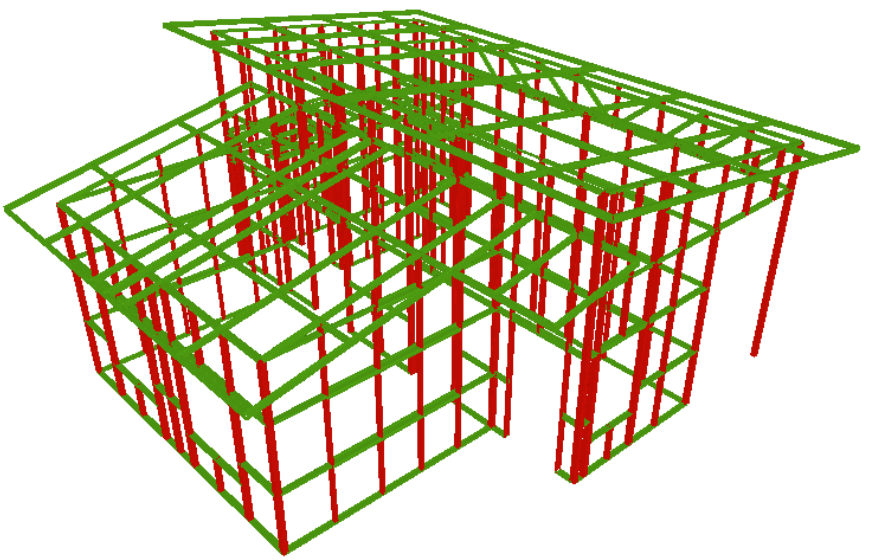


Ribeiro Junior, Edgard; et al; Otimização dos sistemas verticais de vedação em light steel framing para um protótipo de habitação de interesse social. E\&S - Engineering and Science, 2019, 8:2.

\subsection{Processo de dimensionamento}

A estrutura do protótipo foi modelada no programa Metálicas 3D e as ações atuantes na estrutura no edifício determinados de acordo com a NBR 6120:1980 - Cargas para o cálculo de estruturas de edificações (ABNT,1980). Os carregamentos foram divididos em dois grupos: no primeiro, foram identificadas as ações permanentes $(\mathrm{G})$, onde se identificou a cargas como o peso próprio da estrutura e das instalações; no segundo, as cargas variáveis (Q) provenientes do uso da edificação (sobrecargas $-\mathrm{Q}_{1}$ ) bem como aquelas devido as forças vento $\left(\mathrm{Q}_{2}\right)$.

O peso próprio dos painéis de vedação verticais foi identificado de acordo com a composição do sistema de vedação externo e interno seguindo a composição ilustrada na Figura 5. Os pesos dos elementos do sistema foram pesquisados nos catálogos de seus respectivos fabricantes.

Figura 5 - Composição das paredes

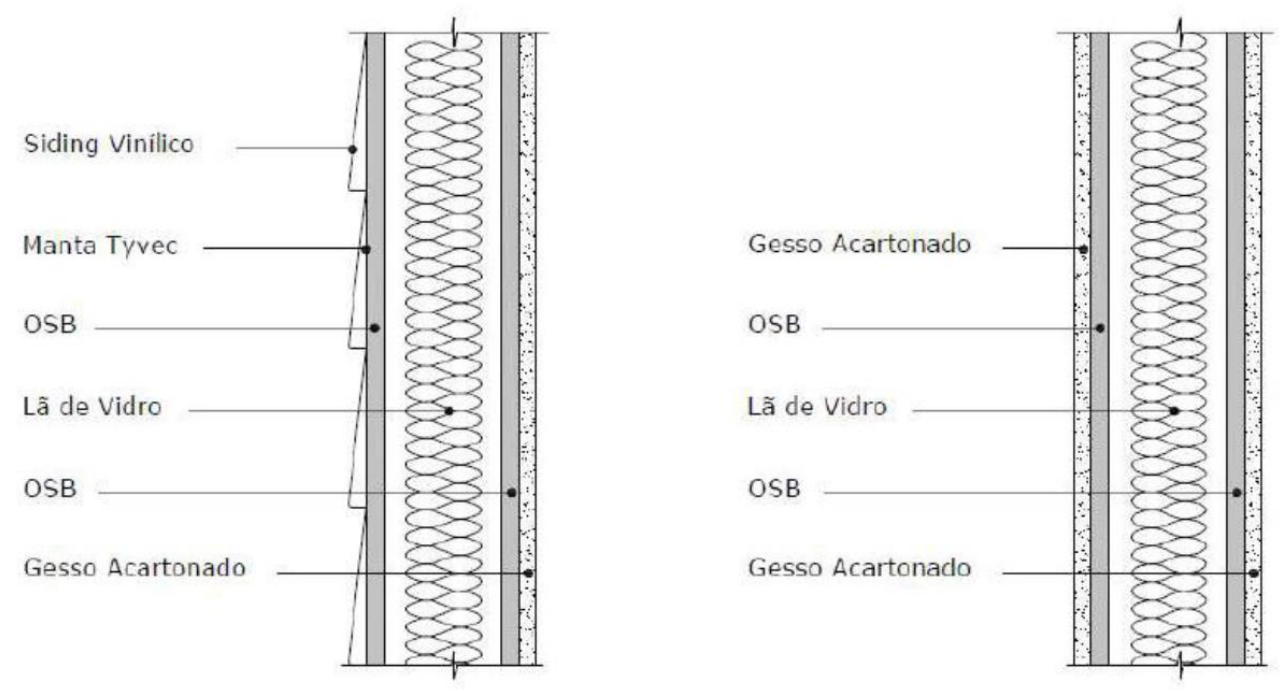

Fonte: Duarte (2017)

O calculo das ações permanentes foi realizada por meio do conceito de área de influencia, de acordo com o espaçamento definido para os montantes. Como relatado, para o edifício em estudo foram adotadas três distâncias distintas: $40 \mathrm{~cm}, 60 \mathrm{~cm}$ e $80 \mathrm{~cm}$. Todo o processo de cálculo foi feito com auxilio de uma planilha eletrônica.

Para o cálculo das forças devido à ação do vento, seguiu-se as especificações da NBR 6123- Forças devidas ao vento em edificações (ABNT,1988). Para a definição da sobrecarga, utilizou-se como referência a NBR 8800 - Projeto de estruturas de aço e de estruturas mistas de aço e concreto de edifícios (ABNT, 2008), bem como a NBR - 8039 - Projeto e Execução de Telhados (ABNT,1983). O dimensionamento dos perfis conformados a frio foi feito por meio da norma ABNT NBR 14762:2010 (ABNT, 2010)

O processo de dimensionamento dos perfis metálicos LSF seguiu a seguinte marcha de cálculo: inicialmente realizou analise estrutural no programa Metálicas 3D, definindo-se para o pré-dimensionamento dos perfis conformados a frio os de menor dimensão disponível para projetos em LSF tendo em vista que se trata de uma edificação térrea; na sequencia, avaliouse a resistência de calculo dos montantes e guias $\left(R_{d}\right)$ que foi comparada com as solicitações de cálculo $\left(\mathrm{S}_{\mathrm{d}}\right)$ identificadas na análise estrutural; Caso a condição de não violação do estado limite de último fosse atendida, o mesmo era considerado estar em conformidade; caso contrário, outro perfis era testado, até que a condição fosse satisfeita. Esta marcha foi conduzida para todas as combinações das ações indicadas anteriormente, até que todos os perfis metálicos atendessem os carregamentos impostos. 
Definidos os perfis a serem utilizados para resistir às solicitações de cálculo em cada espaçamento de montante adotado na pesquisa, a partir dos seus comprimentos e pesos lineares, estimou-se o peso total de cada painel pertencente a estrutura do esqueleto da edificação, conforme indicado na Figura 6. O peso dos paneis foi somado e dividido pela área total do protótipo, obtendo-se os valores das taxas de utilização de aço por metro quadrado para cada valor de espaçamento dos montantes adotados. Com a finalidade de comparar os resultados obtidos, utilizou-se a taxa obtida no projeto desta mesma edificação projetada por Senra (2010) antes das intervenções de melhoria proposta no trabalho de Duarte (2017). Buscou-se, portanto identificar a melhor distribuição de montantes, com vistas a tornar o projeto, tanto econômica quanto tecnicamente, viáveis a partir das propostas de intervenções proposta por Duarte (2017).

Figura 6 - Identificação dos painéis no sistema estrutural idealizado
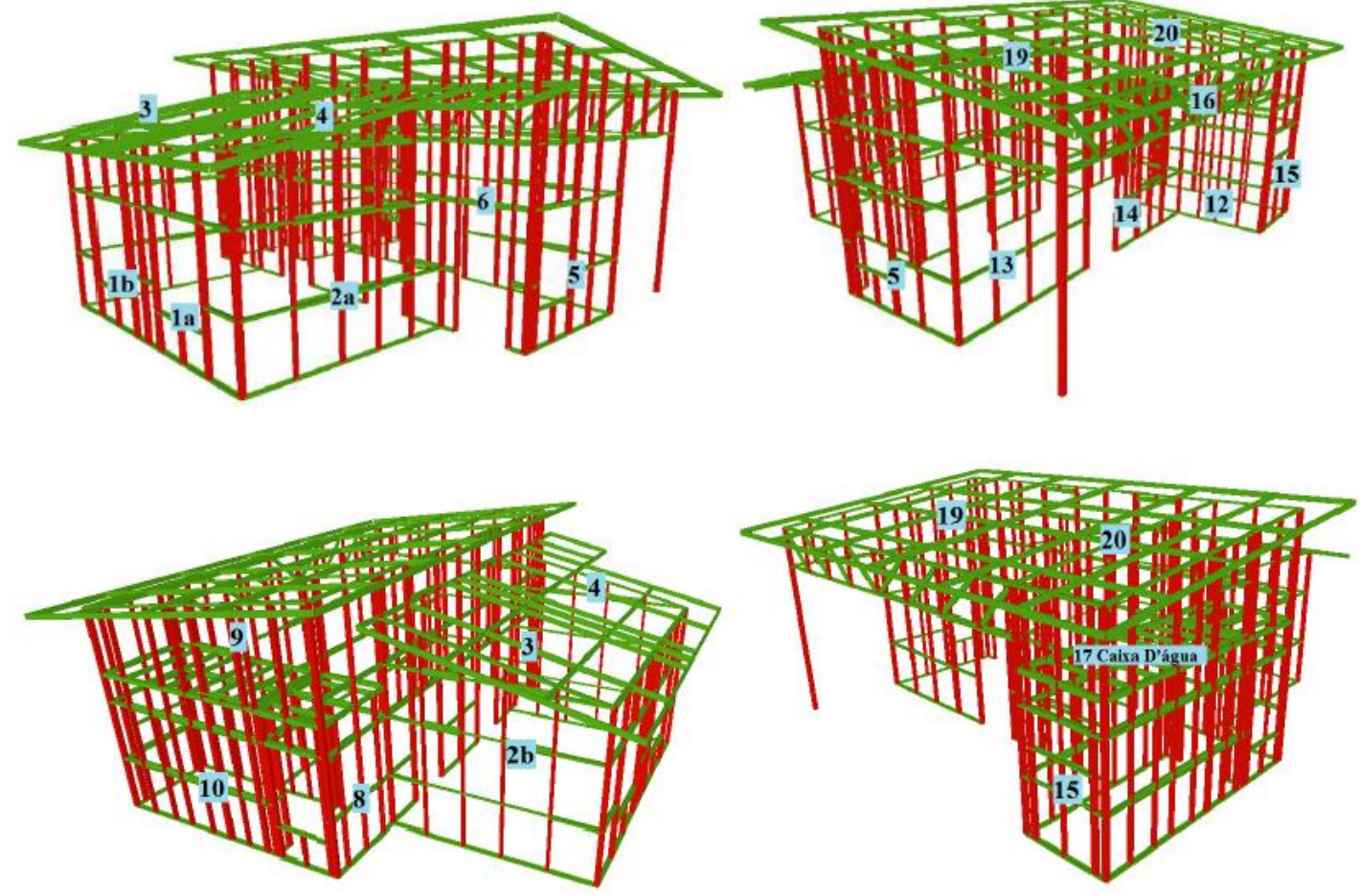

\section{RESULTADOS/ DISCUSSÕES}

Analisando-se o projeto arquitetônico, verificou-se que a disposições dos reservatórios de água ficariam mais bem alocados caso fossem dispostos com 1 metro de distância entre eles, visto que entre estes havia a possibilidade de ser instalado o boiler além de sobrar espaço para possíveis manutenções destas instalações. Desta forma, adotou-se que o primeiro reservatório continuaria em cima do ambiente de circulação e o outro seria realocado na parte superior acima do forro do ambiente do banheiro.

Houve a necessidade de alteração da posição de algumas esquadrias, como as dos quartos visando facilitar a colocação dos montantes nas distâncias desejadas de $40 \mathrm{~cm}, 60 \mathrm{~cm}$ e $80 \mathrm{~cm}$. Além disso, a realocação facilitou o alinhamento do telhado com os montantes. Portanto, algumas esquadrias sofreram deslocamentos de $10 \mathrm{~cm}$ a $20 \mathrm{~cm}$ para as suas laterais em relação ao projeto original da edificação.

Diante disso, percebeu-se durante os dimensionamentos que não seria possível obter 
um protótipo que obedecesse rigorosamente aos respectivos espaçamentos propostos de 40 $\mathrm{cm}, 60 \mathrm{~cm}$ e de $80 \mathrm{~cm}$ tendo em vista que em alguns painéis, como aqueles que continham coberturas, não haveria a necessidade de colocação de perfis espaçados a cada $40 \mathrm{~cm}$ ou 60 $\mathrm{cm}$, mas sim seguindo a recomendação do fabricante das telhas visando a correta instalação das mesmas. Por outro lado, foi verificada a dificuldade em manter espaçamentos de $80 \mathrm{~cm}$ nos painéis do banheiro, visto que as cargas atuantes nas estruturas eram mais elevadas nesta região, obrigando a instalação de painéis com montantes menos espaçados. Fora isso, adotouse os espaçamentos propostos de $40 \mathrm{~cm}, 60 \mathrm{~cm}$ e $80 \mathrm{~cm}$ nos demais painéis, fora aqueles que suportavam o sistema de cobertura e do banheiro, como relatado.

Na Tabela 1 são apresentados o consumo de aço em cada um dos painéis do sistema estrutural adotados para a edificação nos diferentes espaçamentos de montante considerados.

Tabela 1 - Peso dos painéis e peso total de aço consumido nos projetos para os diferentes espaçamentos de montantes considerados

\begin{tabular}{|c|c|c|c|}
\hline $\begin{array}{c}\text { Identificação dos } \\
\text { Painéis }\end{array}$ & $\begin{array}{l}\text { Peso dos painéis } \\
\text { com espaçamento } \\
\text { de } 80 \mathrm{~cm}(\mathrm{~kg})\end{array}$ & $\begin{array}{l}\text { Peso dos painéis } \\
\text { com } \\
\text { espaçamento de } \\
60 \mathrm{~cm}(\mathrm{~kg})\end{array}$ & $\begin{array}{l}\text { Peso dos painéis } \\
\text { com } \\
\text { espaçamento de } \\
40 \mathrm{~cm}(\mathrm{~kg})\end{array}$ \\
\hline $1 \mathrm{a}$ & 49,851 & 49,851 & 58,289 \\
\hline $1 \mathrm{~b}$ & 49,851 & 49,851 & 58,289 \\
\hline $2 a$ & 49,628 & 54,802 & 74,838 \\
\hline $2 b$ & 49,628 & 54,802 & 74,838 \\
\hline 3 & 43,812 & 43,812 & 43,812 \\
\hline 4 & 52,085 & 52,085 & 52,085 \\
\hline 5 & 94,259 & 100,463 & 108,817 \\
\hline 6 & 55,167 & 55,167 & 55,167 \\
\hline 7 & 64,496 & 71,023 & 77,550 \\
\hline 8 & 93,873 & 113,454 & 119,980 \\
\hline 9 & 41,810 & 41,810 & 41,810 \\
\hline 10 & 74,771 & 74,771 & 74,771 \\
\hline 11 & 40,711 & 40,711 & 40,711 \\
\hline 12 & 71,040 & 71,040 & 71,040 \\
\hline 13 & 38,929 & 44,868 & 56,746 \\
\hline 14 & 96,223 & 108,101 & 114,039 \\
\hline 15 & 58,161 & 58,161 & 67,157 \\
\hline 16 & 40,411 & 40,411 & 40,411 \\
\hline 17 & 39,724 & 39,724 & 39,724 \\
\hline 18 & 33,244 & 33,244 & 33,244 \\
\hline 19 & 68,696 & 77,307 & 68,696 \\
\hline 20 & 68,137 & 76,748 & 68,137 \\
\hline 21 & 18,409 & 18,409 & 18,409 \\
\hline 22 & 5,418 & 5,418 & 5,418 \\
\hline TOTAL & $1298,334 \mathrm{~kg}$ & $1376,032 \mathrm{~kg}$ & $1463,980 \mathrm{~kg}$ \\
\hline
\end{tabular}

Por meio da análise da Tabela 1, percebe-se que o consumo total de aço é menor no caso do espaçamento de $80 \mathrm{~cm}$, seguido do espaçamento de $60 \mathrm{~cm}$. Porém, a variação em relação ao espaçamento de $40 \mathrm{~cm}$ não foi tão expressiva, sendo de $20 \%$ em relação ao de 80 $\mathrm{cm}$ e $6,4 \%$ em relação ao de $60 \mathrm{~cm}$. Atribui-se esse comportamento às pequenas dimensões dos ambientes da residência, visto que em vários painéis não foi possível trabalhar o espaçamento sugerido inicialmente, pois as aberturas das esquadrias e o posicionamento das mesmas atrapalhavam o posicionamento do perfil no painel. Outro aspecto importante é a concentração de cargas nas proximidades do banheiro em virtude dos reservatórios de água. Para o dimensionamento, foi necessário diminuir o espaçamento dos painéis que circundavam o banheiro, fazendo com que a distância ficasse muito próxima dos $40 \mathrm{~cm}$. Devido a estes 
Ribeiro Junior, Edgard; et al; Otimização dos sistemas verticais de vedação em light steel framing para um protótipo de habitação de interesse social. E\&S - Engineering and Science, 2019, 8:2.

fatores, percebe-se por meio da Tabela 1 que mesmo variando o espaçamento, diversos painéis se mantiveram com os pesos praticamente inalterados.

A grande vantagem em se trabalhar com maiores espaçamentos de montante, como os de $80 \mathrm{~cm}$, foi o fato de que em painéis com baixa solicitação, painéis cegos (aqueles que não apresentam janelas e portas) ou com pouca abertura, possibilitam a redução do consumo de aço uma vez que nestes são utilizados uma menor quantidade de montantes. Desta forma, a redução em termos de quantidade alcançada no protótipo com montantes a cada $80 \mathrm{~cm}$ foi de $11,31 \%$ em comparação com o de espaçamento de $40 \mathrm{~cm}$.

Com relação à taxa de consumo de aço (Tabela 2), ao se comprar os valores obtidos neste trabalho com o projeto desenvolvido por Duarte (2017) com aquela projetada por Senra (2010) com espaçamento tradicional de $60 \mathrm{~cm}$, nota-se que os valores ficaram muito próximos, sendo que no presente trabalho, o consumo ficou ligeiramente inferior, apenas $2,27 \%$. Já em comparação com o espaçamento de $40 \mathrm{~cm}$ em relação ao protótipo proposto por Senra (2010), percebe-se que o de este consumiu 3,98\% a menos. Por outro lado, se compararmos o protótipo otimizado com espaçamento de $80 \mathrm{~cm}$, percebe-se redução de $7,98 \%$.

Tabela 2 - Taxa de consumo de aço para os diferentes espaçamentos projetados e projetado por Senra (2010)

\begin{tabular}{c|c|c|c|c}
\hline & $\mathbf{8 0} \mathbf{~ c m}$ & $\mathbf{6 0} \mathbf{~ c m}$ & $\mathbf{4 0} \mathbf{~ c m}$ & Senra (2010) \\
\hline Aço consumido $(\mathrm{kg})$ & 1298,33 & 1376,03 & 1463,98 & 1074,76 \\
\hline Área construída $\left(\mathrm{m}^{2}\right)$ & 59,24 & 59,24 & 59,24 & 45,22 \\
\hline $\begin{array}{c}\text { Taxa de consumo de aço } \\
\left(\mathrm{kg} / \mathrm{m}^{2}\right)\end{array}$ & 21,91 & 23,22 & 24,71 & 23,76 \\
\hline
\end{tabular}

\section{CONCLUSÃO}

O presente buscou quantificar o consumo de aço em um projeto de habitação desenvolvido considerando implementações de mudanças por Duarte (2017) em relação ao projeto inicial dimensionado por Senra (2010). Verificou-se que a possiblidade de modificar o espaçamento dos montantes no projeto em Light Steel Frame afetou as taxas de consumo de aço no projeto da edificação.

Para o projeto pesquisado, espaçamentos maiores do que aqueles recomendados pela literatura consumiram uma menor taxa de consumo de aço. Para o espaçamento de $80 \mathrm{~cm}$, a taxa de consumo de aço ficou 7,98\% menor do que aquele obtido com $60 \mathrm{~cm}$ utilizado no projeto inicial do protótipo. Com os montantes espaçados a cada $80 \mathrm{~cm}$ em relação ao de 40 $\mathrm{cm}$, foi possível obter um resultado satisfatório com redução de até $11,31 \%$ menor no consumo de aço.

Porem, um aspecto importante a ser considerado é que o espaçamento dos montantes não deve ser apenas um dos fatores a ser levado em consideração uma vez que as dimensões dos elementos que integram o painel influenciam na definição dos mesmos. Desta forma, é importante salientar que o presente trabalho não avaliou a questão construtiva do painel, visto que o espaçamento de $80 \mathrm{~cm}$ poderia dificultar a instalação das placas de OSB para a vedação. Além disso, como a dimensão comercial das placas de OSB é de 1,20 × 2,40 m, ela é adequada para ser posicionada caso o espaço entre dois montantes seja o convencional, ou seja, de $60 \mathrm{~cm}$, mas não o de $80 \mathrm{~cm}$. Desta forma, torna-se pensar novas alternativas para a fixação destas placas, como por exemplo, mudança na posição de fixação das placas que, ao invés de serem instaladas na posição vertical, poderia ser fixada na horizontal, possibilitando explorar melhor a sua maior dimensão de $2,40 \mathrm{~m}$, a qual que seria adequada para $\mathrm{o}$ espaçamento de três montantes com $80 \mathrm{~cm}$. 
Ribeiro Junior, Edgard; et al; Otimização dos sistemas verticais de vedação em light steel framing para um protótipo de habitação de interesse social. E\&S - Engineering and Science, 2019, 8:2.

\section{REFERÊNCIAS}

ABRÃO, R. M. Sistemas de estruturados em aço para habitação de interesse social Light Steel Framing. 2008. TCC (Graduação). 73f. Curso de Engenharia Civil, Universidade Federal de Mato Grosso, Cuiabá, 2008.

ASSOCIAÇÃO BRASILEIRA DE NORMAS TÉCNICAS. NBR 6120: Cargas para o cálculo de estruturas de edificações. Rio de Janeiro, 1980. 5 p.

NBR 6123: Forças devidas ao vento em edificações. Rio de Janeiro, 1988. 66p.

NBR 8800: Projeto de estruturas de aço e de estruturas mistas de aço e concreto de edifícios. 2 ed. Rio de Janeiro, 2008. 237p.

NBR 14762: Dimensionamento de estruturas de aço constituídas por perfis formados a frio. 2 ed. Rio de Janeiro, 2010. 87p.

DUARTE, D. R. Habitação Social em Light Steel Framing como Proposta de Construção Sustentável. 2017. Dissertação (Mestrado). 187f. Programa de Pós-graduação em Engenharia de Edificações e Ambiental, Faculdade de Arquitetura, Engenharia e Tecnologia, Universidade Federal de Mato Grosso, 2017.

RODRIGUES, F. C.; CALDAS, R. B. Steel Framing: Engenharia. 2 ed. Rio de Janeiro: CBCA, 2016. 224p.

SANTIAGO, A. K.; FREITAS, A. M. S.; CRASTO, R. C. M.; Steel Framing: Arquitetura. 2012. Rio de Janeiro, Instituto Aço Brasil - CBCA (Série Manual de Construção em Aço). $151 \mathrm{p}$.

SENRA, Rodrigo Ferreira. Desenvolvimento de um projeto de habitação de interesse social em Light Steel Framing. 2010. TCC (Graduação). 90f. Curso de Engenharia Civil, Universidade Federal de Mato Grosso, Cuiabá, 2010.

SILVA, E. L.; PIERIN, I.; SILVA, V. P. Estruturas compostas por perfis formados a frio - Dimensionamento pelo método das larguras efetivas e aplicação conforme ABNT NBR 14762:2010 e ABNT NBR 6355:2012. Rio de Janeiro: CBCA, 2014. 192p. 